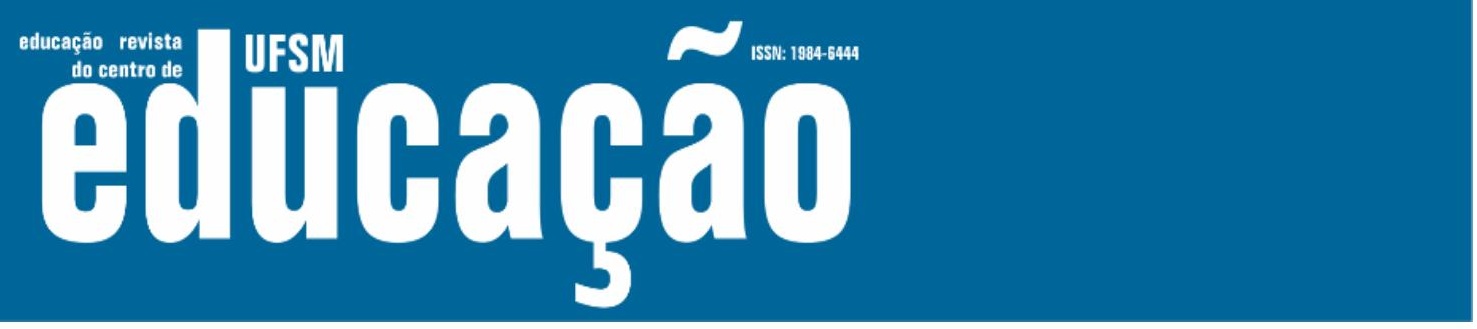

ISSN: 1984-6444 | http://dx.doi.org/10.5902/1984644444292

\title{
A arte da desaparição como experimentação tateante de pensamento: contribuições à pesquisa educacional
}

The art of disappearance as a groping thought experiment: contributions to educational research

Christian Fernando Ribeiro Guimarães Vinci

Professor Doutor na Universidade do Estado de Minas Gerais. Divinópolis, Minas Gerais, Brasil. christian.guimaraes.vinci@gmail.com - http://orcid.org/0000-0003-2914-3032

Cintya Regina Ribeiro

Professora Doutora na Universidade de São Paulo. São Paulo, São Paulo, Brasil. cintyaribeiro@usp.br - http://orcid.org/0000-0002-7924-4539

Recebido em 14 de maio de 2020

Aprovado em 03 de agosto de 2020

Publicado em 04 de setembro de 2021

\section{RESUMO}

O artigo tem como objetivo discutir as implicações da forma ensaística de pensamento para o campo da pesquisa educacional. A partir da triangulação de forças entre o pensamento de Michel de Montaigne, Enrique Vila Matas e Gilles Deleuze-Félix Guattari, o estudo explora de que modo, na aurora da subjetividade moderna, certa arte do retrato, produzida a partir da forma ensaística desenvolvida por Montaigne, permitiu a emergência de um modo de experimentação tateante do pensamento, cujo horizonte se volta a uma condição de desaparição. $O$ trabalho visa esmiuçar essa distinta arte do retrato dedicada à desaparição, focando-se em sua potência fabulatória, bem como explorar suas ressonâncias nos modos como concebemos o ofício do pesquisador, sobretudo no campo educacional, em contraposição a outra arte de retrato denominada cartesiana. Por fim, a discussão aponta que a desaparição, ao instaurar outra geografia de pensamento, possibilita ao pesquisador educacional mobilizar procedimentos outros tendo em vista ensaiar o impensável.

Palavras-chave: Desaparição; Ensaio; Pesquisa Educacional.

\section{ABSTRACT}

This article aims to discuss the so-called essayistic form of thinking and its impact for the field of educational research. From the triangulation of forces between the thinking of Michel de Montaigne, Enrique Vila Matas and Gilles Deleuze-Felix Guattari, the study explores how, in the dawn of modern subjectivity, a certain art of portraiture produced from the essayistic form developed by Montaigne, produces a 


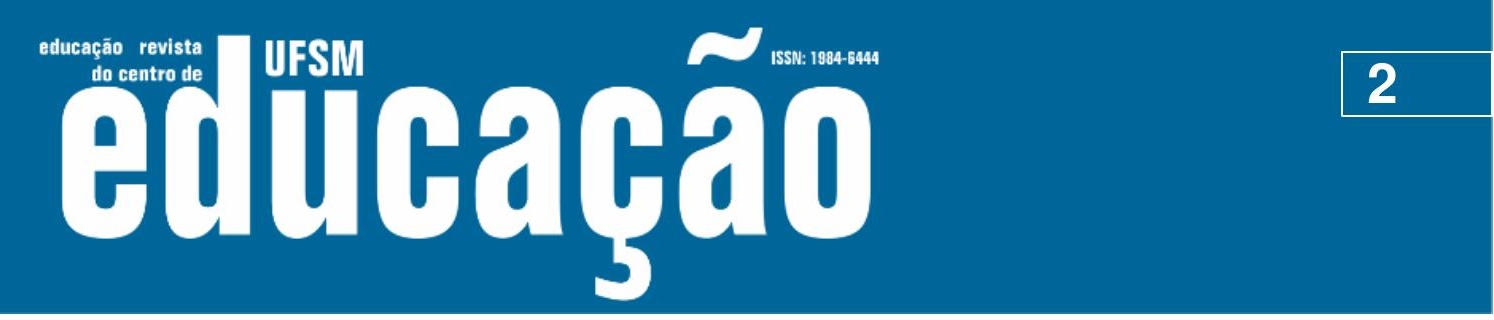

ISSN: 1984-6444 | http://dx.doi.org/10.5902/1984644444292

groping mode of thought experimentation whose horizon turns to a condition of disappearance. This work aims to study this distinctive portrait art dedicated to disappearance, focusing on its fabulous power, as well as explore its resonances in the ways we conceive the researcher's craft, especially in the educational field, as opposed to another portrait art called cartesian and developed by René Descartes. The discussion points out that the disappearance, by establishing another geography of thought, enables the educational researcher to mobilize other procedures in order to research the unthinkable.

Keywords: Disappearance; Essay; Educational Researche.

\section{Introdução}

"Uma coisa em todo o caso é certa: é que o homem não é o mais velho problema nem o mais constante que se tenha colocado ao saber humano. (...) $O$ homem é uma invenção cuja recente data a arqueologia de nosso pensamento mostra facilmente", asseverou Michel Foucault (1999, p. 536) em As Palavras e as Coisas. Esse seria um fato inconteste, argumenta o filósofo, e seria possível apostar que, muito em breve, o homem desapareceria "como, na orla do mar, um rosto de areia" (FOUCAULT, 1999, p. 536). Retomando o prognóstico foucaultiano, Enrique Vila-Matas (2009) também buscou sondar a trágica fortuna do homem, figura nascida sob o signo do esvaecimento. $O$ desaparecimento, compreendido pelo escritor catalão como uma irrefreável sina, marcou indelevelmente os dois grandes marcos da modernidade: os Ensaios, de Michel de Montaigne, e as Meditações Metafísicas, de René Descartes.

Vila-Matas recorda que Montaigne, ao escrever os seus Ensaios, enclausurou-se em uma das torres de seu castelo em Bordeaux, isolou-se do mundo e desfrutou de uma relativa tranquilidade para poder pintar-se em palavras. Não almejava "o favor do mundo" e, por esse motivo, mostrava-se em sua "maneira mais simples, natural e habitual, sem apuro e artifício" (MONTAIGNE, 2002, p. 4). Aconselhava o seu leitor: "não é sensato que empregues teu lazer em um assunto tão frívolo e tão vão" (MONTAIGNE, 2002, p. 4). Não raro, surgem certas construções coloquiais, destoantes da alta erudição demonstrada pelo ensaísta e 


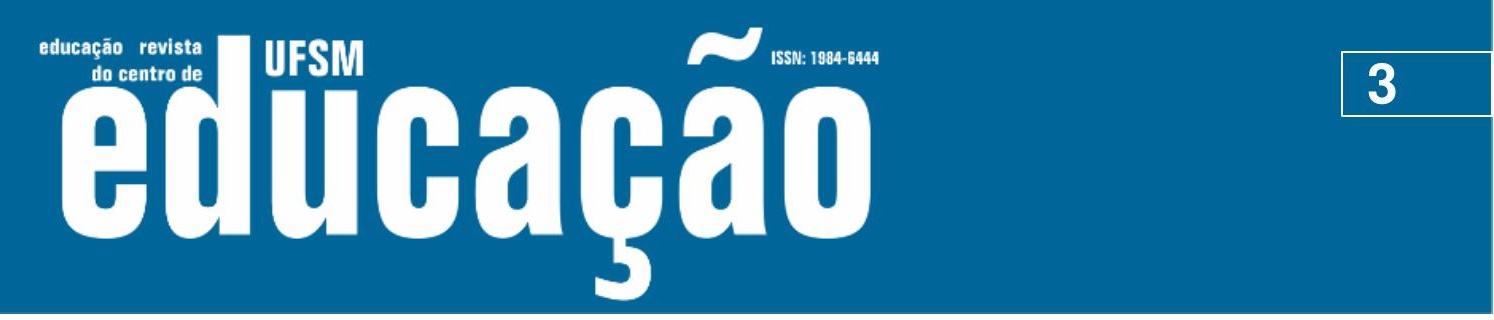

ISSN: 1984-6444 | http://dx.doi.org/10.5902/1984644444292

passíveis de ilustrar aquela ausência de apuro e artifício propagada pelo escritor em sua apresentação. Dentre as expressões montaignianas, Vila-Matas (2009) ressalta a seguinte: "roubemos espaço aqui para uma história" (MONTAIGNE, 2002, p. 167). Esse recurso popularesco, argumenta o escritor catalão, possibilitaria inserir um relato qualquer no interior de reflexões filosóficas mais densas. Por meio dessas fórmulas singelas, Montaigne conferia movimento e velocidade ao seu pensar e, ademais, transmutava as mais altas sabedorias em simples prosa. Uma reflexão conferia espaço para uma ou outra banalidade que, por sua vez, permitia o surgimento de um relato pessoal e este, por seu turno, apontava para uma ponderação filosófica. No "Eu" mais profundo de Montaigne, parecia pulsar o mundo. O retrato pintado pelo ensaísta parece carecer de clareza e precisão. Os devaneios mais diversos ou os relatos mais triviais o encantavam e acabavam por conduzir sua narrativa por caminhos pouco ou nada convencionais. Em determinada altura de sua obra, Montaigne não se furta a dizer:

\footnotetext{
Os outros formam o homem; eu o descrevo, e reproduzo um homem particular muito mal formado e o qual, se eu tivesse de moldar novamente, em verdade faria muito diferente do que é. Mas agora está feito. Ora, os traços de minha pintura não se extraviam, embora mudem e diversifiquemse. O mundo não é mais que um perene movimento. (...) Não consigo fixar meu objeto. Ele vai confuso e cambaleante, com uma embriaguez natural. Tomo-o nesse ponto, como ele é no instante em que dele me ocupo. Não retrato o ser. Retrato a passagem. (...) Se minha alma pudesse firmar-se, eu não me ensaiaria: decidir-me-ia; ela está sempre em aprendizagem e em prova. (MONTAIGNE, 2002, p. 27-8)
}

Trata-se de uma curiosa arte do retrato, preocupada em apreender a passagem. Uma arte que, conforme argumentou Vila-Matas (2009), contrapor-seia àquela dita cartesiana. René Descartes também optou pela clausura, trancafiando-se em um lugar solitário de Ulm para escrever seus textos. Estes, contudo, não partilham do mesmo impulso presente nos escritos de Montaigne. Em suas Meditações Metafísicas, por exemplo, Descartes (2011) adotou uma visão mais sóbria, acreditando que qualquer devaneio ou coloquialismo seria uma forma de se desviar do seu "Eu" e, por conseguinte, da verdade. Não por outro motivo, ao 


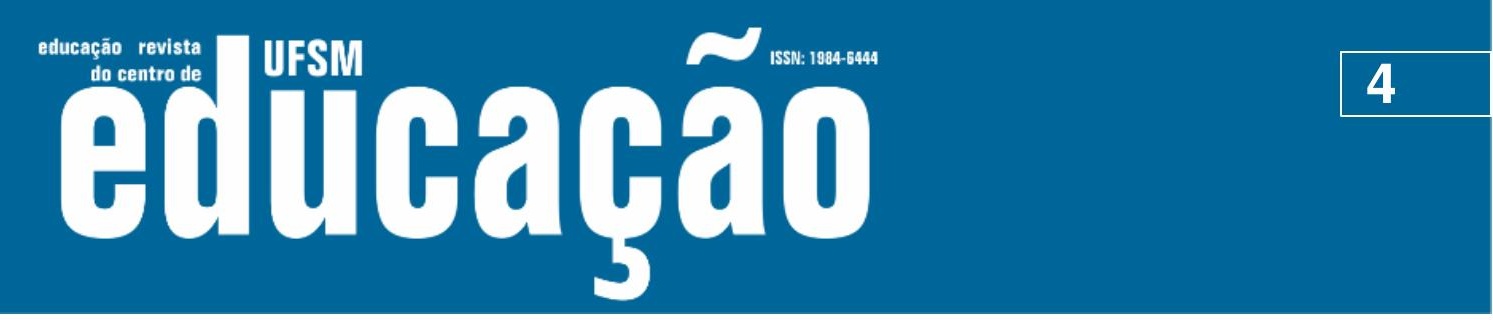

ISSN: 1984-6444 | http://dx.doi.org/10.5902/1984644444292

refletir sobre qual a melhor arte do retrato que um pintor deveria adotar, argumentou:

\begin{abstract}
Os pintores, mesmo quando se esforçam com o maior artifício em representar sereias e sátiros com formas esquisitas e extraordinárias, não Ihes pode, todavia, atribuir formas e naturezas inteiramente novas, mas fazem somente certa mistura e composição dos membros de diversos animais; ou então, se talvez sua imaginação for bastante extravagante para inventar algo de tão novo que jamais tenhamos visto nada de semelhante, e que assim sua obra nos represente uma coisa puramente fingida e absolutamente falsa, por certo no mínimo as cores com que eles o compõem devem ser verdadeiras. (DESCARTES, 2011, p. 33-34)
\end{abstract}

Descartes esconjura o ímpeto fabulatório do pensamento e busca fiar-se apenas em sóbrios elementos, matematicamente inquestionáveis. Frutos de um gênio maligno, qualquer distração - sentidos, devaneios, sonhos etc. - deve ser calada em prol do mais simples e do mais verdadeiro, do imutável e do estático. Diferentemente de Montaigne, interessado em entregar-se aos loucos devaneios de seu pensamento. Não por outro motivo, em Da ociosidade, lemos:

[Meu espírito] engendra-me tantas quimeras e monstros fantásticos, uns sobre os outros, sem ordem e sem propósito, que para examinar com vagar sua inépcia e estranheza comecei a registrá-los por escrito, esperando com o tempo fazer que se envergonhe de si mesmo por causa deles. (MONTAIGNE, 2002, p.46)

$\mathrm{Na}$ aurora da subjetividade moderna, em resumo, deparamos com duas artes do retrato, distintas e singulares. Uma, dita cartesiana, preocupada em captar o ser em sua pretensa essência imutável e verdadeira. Outra, ensaística, buscando entregar-se aos ébrios movimentos do pensar. Em ambas presentifica-se o risco do desaparecimento vislumbrado tanto por Foucault (1999) quanto por Vila-Matas (2009). No primeiro caso, o desaparecer do homem estaria atrelado às ilusões impostas pelos sentidos, pelos sonhos ou por um gênio maligno qualquer; no segundo, desaparecer seria uma espécie de inevitável movimento do próprio pensamento. Para Descartes, desaparecer é um problema a ser evitado; para Montaigne, um ponto a ser atingido. 


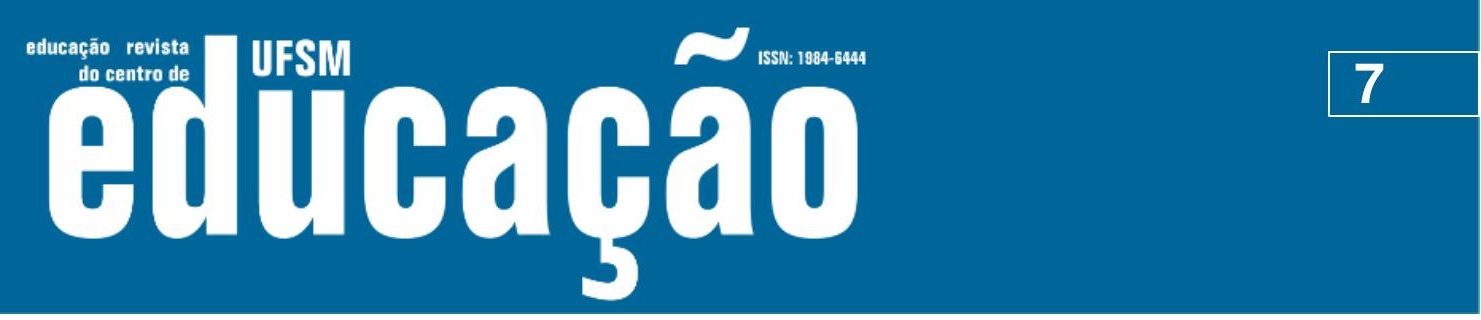

ISSN: 1984-6444 | http://dx.doi.org/10.5902/1984644444292

Perder teorias, diz-nos Vila-Matas (2010), seria algo essencial para 0 exercício do pensamento. Para aqueles que primam por mover-se nas chamadas regiões inferiores, não existiria um alhures ou algo similar, apenas movimentos e devires. Para captá-los, precisamos criar um espaço outro, um "fora-daqui". Poderíamos dizer que, aqui, não se trata de vislumbrar um além-mundo, tal qual Descartes, acessando uma imagem de um lugar mais verdadeiro ou perfeito; tratase de habitar o espaço do vivido com suas baixezas e impurezas, ou seja, apossarse das forças constitutivas de nosso mundo de modo a transmutá-las em algo impensável. Para tanto, convém escapar dos desmandos do cogito, dos imperativos da razão e buscar acessar uma zona nebulosa na qual não há nada senão fabulações e invenções, senão aquilo mesmo que poderíamos considerar como pensamento. As teorias e metodologias, elementos importantes da arte cartesiana, atam-nos linearmente ao cotidiano, obrigando-nos a focalizar o estático e o imutável, produzindo, assim, um instantâneo do mundo; uma arte ensaística como a de Montaigne, por sua vez, produz um fluxo voraz de pensamento, a partir do qual o impensável pode passar a ser ensaiado, por meio da criação de procedimentos singulares.

Foi Gilles Deleuze (1988) quem, certa vez, atestou o lastro criativo do pensamento. Defende o filósofo que apenas ao acessarmos o impensável, aquilo que não encontra referência no platônico mundo sensível ou das ideias, passamos realmente a pensar. Poderíamos aproximar a arte de Montaigne de um tal preceito? Acreditamos que sim. Vejamos. O pensamento, prossegue Deleuze, é de ordem intensiva, jamais extensiva - não obstante o privilégio da sensibilidade para sua produção:

O pensamento só pensa coagido e forçado, em presença daquilo que "dá a pensar", daquilo que existe para ser pensado - e o que existe para ser pensado é do mesmo modo o impensável ou o não pensado, isto é, o fato perpétuo que "nós não pensamos ainda". É verdade que, no caminho que leva ao que existe para ser pensado, tudo parte da sensibilidade. Do intensivo ao pensamento, é sempre por meio de uma intensidade que o pensamento nos advém. $O$ privilégio da sensibilidade como origem aparece nisso: o que força a sentir e aquilo que só pode ser sentido são uma mesma coisa no encontro, ao passo que as duas instâncias são distintas nos outros casos. (DELEUZE, 1988, p. 210) 


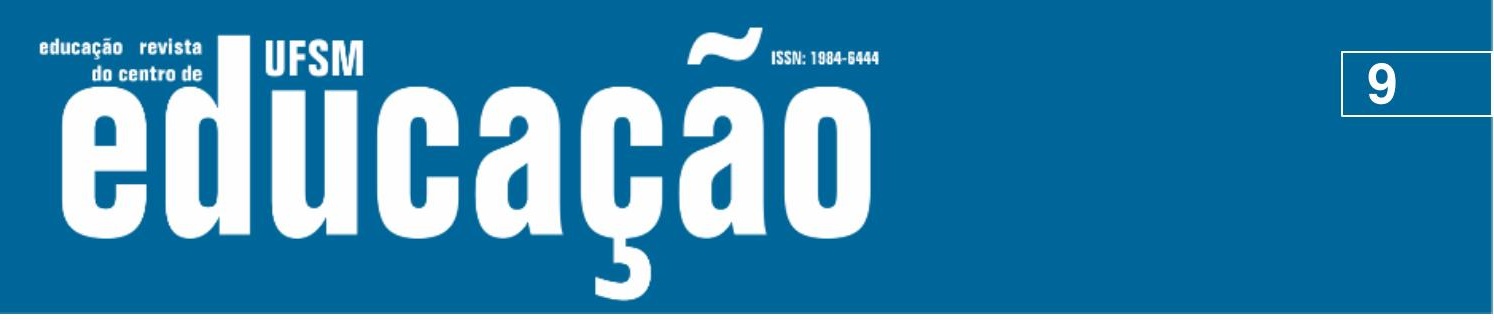

ISSN: 1984-6444 | http://dx.doi.org/10.5902/1984644444292

A questão que fica, pois, é: como acessar esses movimentos terríveis? Em primeiro lugar, prossegue Deleuze, seria preciso "engendrar pensar no pensamento" (1988, p. 174). Para isso, seria necessário escaparmos da imagem dogmática de pensamento, aquela mesma propagada por homens como Descartes, livrando-nos de seus pressupostos e criando um "fora-daqui". Como bons pintores, precisaríamos começar limpando os clichês de nossas telas, como nos instiga Deleuze:

O pintor tem várias coisas na cabeça, ao seu redor ou no ateliê. Ora, tudo o que tem na cabeça ou ao seu redor já está na tela, mais ou menos virtualmente, mais ou menos atualmente, antes que ele comece o trabalho. Tudo isso está presente na tela, sob a forma de imagens, atuais ou virtuais. De tal forma que o pintor não tem de preencher uma superfície em branco, mas sim esvaziá-la, desobstruí-la, limpá-la. Portanto, ele não pinta para reproduzir na tela um objeto que funciona como modelo: ele pinta sobre imagens que já estão lá, para produzir uma tela cujo funcionamento subverta as relações do modelo com a cópia. Em suma, o que é preciso definir são todos esses "dados" que estão na tela antes que o trabalho do pintor comece. E, entre esses dados, quais são um obstáculo, quais são uma ajuda ou mesmo os efeitos de um trabalho preparatório. (2007a, p. 91)

Encontramos ressonâncias, nessa imagem deleuziana, com a discussão de Vila-Matas sobre perda de teorias. Para o autor catalão (2010) a escrita só acontece quando a permitimos seguir seus próprios rumos ou quando deixamos de imaginar o que escreveríamos caso escrevêssemos e passamos simplesmente a escrever. As metodologias, nesse sentido, podem ser danosas, uma vez que estão carregadas de pressupostos sobre como escrever ou pensar. Enchem, portanto, a folha em branco de modelos e orações pré-formatadas. Ora, não sabemos de antemão como uma escrita acontece, como estabelece seus próprios caminhos, e tampouco do que seria capaz. Para responder a isso, seria preciso enfrentar, afirmativamente, o ato mesmo de escrever em luta com os clichês.

Vila-Matas (2010), ao esvaziar a página em branco e buscando construir seu "fora-daqui", propõe abdicarmos de qualquer teoria ou metodologia, para que possamos adotar procedimentos. Por meio do estabelecimento de conexões diversas - Vila-Matas, por exemplo, escreve seus textos distorcendo citações 


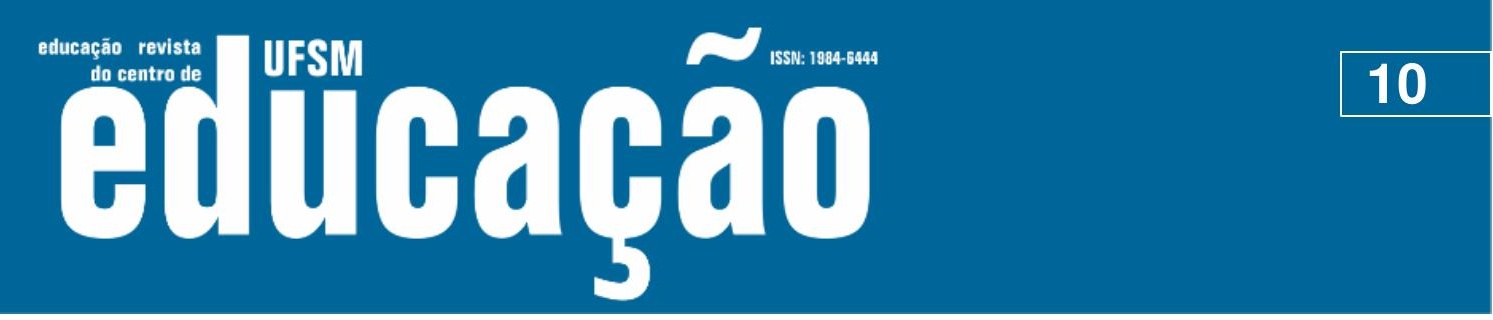

ISSN: 1984-6444 | http://dx.doi.org/10.5902/1984644444292

literárias e filosóficas, algumas inventadas por ele -, o procedimento permitiria a criação de ocasiões para a escrita, situações nas quais somos conduzidos pelos fluxos fabulatórios dos próprios movimentos escriturais. Diferentemente do método, o procedimento é informe. Não possui pressupostos, tampouco regras ou ponto de chegada. Acredita piamente nesse mundo, procurando habitá-lo, sendo o seu único compromisso com as forças criativas das regiões insuspeitas.

Um procedimento, diante da folha em branco, brinca com os elementos que já estariam lá de maneira virtual: ora permitindo à escrita encontrar-se com um ou outro vetor de força capaz de potencializar o escrever, conduzindo-nos forçosamente a zonas de fabulação; ora os descartando, por impedirem os devaneios. O procedimento, como argumenta Deleuze (1997), nada mais é do que a escrita em processo. Processo infinito, incapaz de ser domado, tal qual o pensamento. Processo que surge quando, paradoxalmente, desaparecemos com o "Eu", com o cogito, e com toda e qualquer metodologia. Se, caso optemos por embrenharmo-nos nessa vereda, não há método ou caminho seguro, tampouco modos de domar o pensamento-escrita, como prosseguir? Talvez seja preciso uma mudança de posição, uma conversão radical a certo empirismo, abrindo mão de qualquer porto seguro.

\section{A arte do ensaio como um empirismo radical}

Em Do costume - e de não mudar facilmente uma lei aceita, Montaigne compartilha o seguinte relato com o leitor:

\footnotetext{
Roubemos espaço aqui para uma história. Um fidalgo francês sempre se assoava com a mão - coisa muita avessa ao nosso costume. Acerca disso, defendendo sua atitude (e era famoso pelos ditos espirituosos), ele perguntou-me que privilégio tinha aquela suja excreção para que the fôssemos preparando um belo lenço delicado a fim de recebê-la e depois, o que é pior, empacotá-la e guardá-la cuidadosamente em nós; que isso devia causar mais horror e náusea do que vê-la ser lançada fora de qualquer maneira, como fazemos com todas as outras excreções. Achei que ele não falava totalmente sem razão e que o costume me eliminara a percepção dessa extravagância, que no entanto consideramos tão horrível quando é narrada a propósito de outro país. (MONTAIGNE, 2002, p. 167)
} 


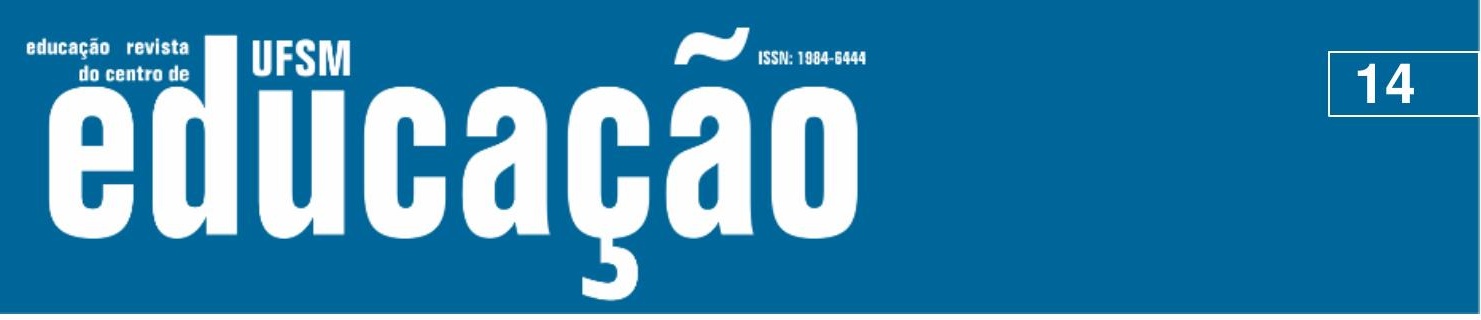

ISSN: 1984-6444 | http://dx.doi.org/10.5902/1984644444292

dito cogito. Por já portar uma imagem do que significa pensar e por almejar atingir um alhures, o cogito impediria nossa conversão ao povoar o plano de imanência com memórias, valores e opiniões, com uma imagem de pensamento construída de véspera. Tal modo operatório da ciência cartesiana possuiria implicações políticas e epistemológicas para aqueles que buscam problematizar imagens de pensamento, sobretudo quando remetemos às práticas de pesquisa e nos encontramos implicados ao empirismo radical de um Montaigne ou de um Deleuze e Deleuze-Guattari. Nesse sentido, buscamos discutir, a seguir, as ressonâncias das discussões aqui apresentadas para o campo das pesquisas educacionais.

\section{Ressonâncias educacionais}

Para Nadja Prestes (1997) em sua obra Metafísica da subjetividade na educação: as dificuldades do desvencilhamento, a geografia do cogito teria determinado o espaço do pensável em Educação e os modos de viver juntos. Pensar seria, partindo da certeza de que verdades existem, refletir sobre os melhores modos de conviver em companhia de outrem a partir de um referencial pré-estabelecido e moldar, assim, a ação educativa visando atingir esses fins. A razão, desse modo, transmutar-se-ia em razão instrumental, sendo utilizada de forma a domar a potência criativa do mundo. Para Prestes (1997), vigoraria no modelo educacional fundado nessa arte cartesiana um dever ser, pautado numa ideia de um sujeito racional capaz de ser educado para se tornar um ente autônomo. O cogito cartesiano, essa essência partilhada pelos seres racionais, legitima o edifício pedagógico, cuja principal função é autonomizar os sujeitos, ou adequá-los a certa imagem de sociedade. Domá-los em seu pensar e em seu sentir. $\mathrm{Na}$ arte cartesiana do retrato, como vimos, há o risco da perdição, do desaparecimento do "Eu"; mas esse risco pode e deve ser evitado por meio de uma boa educação. Essa arte, por conseguinte, implicaria de largada uma necessidade de obedecermos a valores e costumes formatados de véspera. Não por outra razão, o edifício pedagógico moderno, aquele herdado por nós, imbui-se de uma série de tarefas de acento metafísico. 


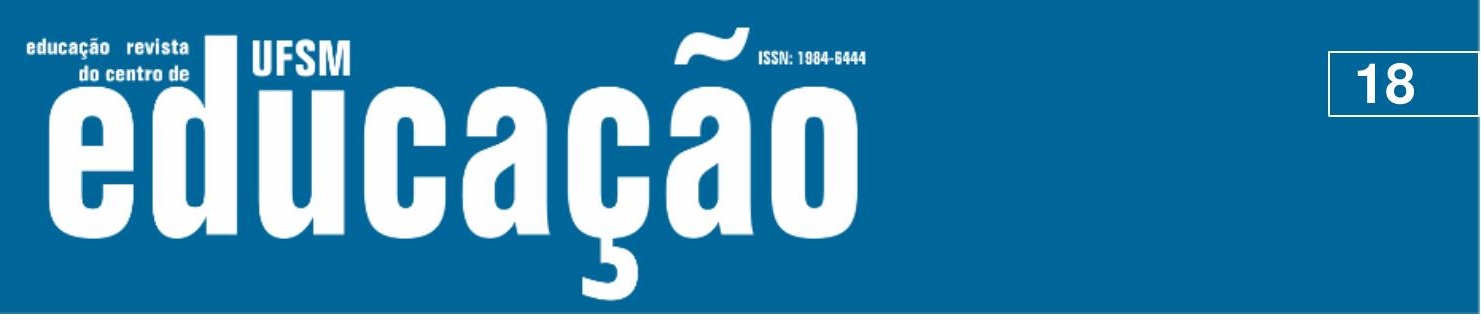

ISSN: 1984-6444 | http://dx.doi.org/10.5902/1984644444292

ao pensamento não caberia a condição pacífica de guardião da cultura e dos valores modernos, fazendo reverberar a conformidade do homem com supostas ontologias do mundo e de si. Refratário a qualquer modo de complacência diante das condições do viver, o pensamento seria de qualidade eminentemente combativa: um vetor de força que se faria contínuo no jogo do poder, produzindo a transgressão do pensável como gesto incondicional de resistência. (RIBEIRO, 2011, p. 620)

Como um vetor de força, talvez caiba ao pensamento tensionar os procedimentos há muito estabelecidos, afrontando o império do costume. Nesse sentido, não poderia furtar-se aos embates nas relações de poder. O pensamento seria, pois, da ordem da transgressão. Transgredir como um modo de atacar o intolerável, mas não visando produzir outro mundo, melhor e mais verdadeiro, mas buscando construir outra relação com esse mundo mesmo, por meio da forja de outra sensibilidade. Acreditar nesse mundo seria a principal tarefa desse outro modo de pensar - forjar e sustentar esse espaço que se faz como um "fora-daqui" e que implicaria na construção de condições que se abram às forças do impensável, ou, poderíamos dizer, na abertura a um plano de imanência.

Pesquisar, nesse diapasão, não implicaria um modo de fomentar melhorias nesse suposto real intolerável, numa visão meramente reformista. Numa perspectiva de imanência, pesquisar diz respeito a potencializar a relação dos homens com o mundo que habitam. Cada vivente possuiria uma relação única com o mundo, passível tanto de ser calada e uniformizada pela cultura quanto potencializada em sua singularidade. Para essa potencialização, seria preciso fazer durar esse espaço criado por cada qual e, para tanto, convém estabelecer conexões vitais que the deem sustentação. Permitir ao impensável surgir e perseverar, pois. Ao pesquisador, por conseguinte, não caberia o papel de ordenar processos a partir de um olhar exterior, adequando o trabalho investigativo a uma norma padrão estabelecida culturalmente e partilhada pelo senso comum. Diferentemente, sua tarefa diz respeito a acompanhar e potencializar distintos processos. Vitalizá-los, pois.

Modifica-se o terreno, modifica-se a geografia. Não são mais as coordenadas do cogito, mas uma coordenada que experimenta tatear linhas e processos. Modifica-se o modo operatório dessa ciência: "o objeto-processo requer 
ISSN: 1984-6444 | http://dx.doi.org/10.5902/1984644444292

A cena tende a se repetir: professores limitados a reproduzir antigos métodos de ensino e avaliação (tais como a reprodução mecânica de roteiros, planos de aula, mimeógrafos sem vida e sem inovação); alunos e crianças, desde cedo, apartados de seu espírito artístico, alegre, curioso, inventivo são conduzidos para a rigidez do cumprimento do dever, de tarefas e horários desprezíveis. (COSTA, 2011, p. 280)

Em vez de conectar e comparar a cena com uma imagem do que seria uma boa educação ou um bom espaço escolar, tratar-se de ia de conclamar experimentações. Assim, um novo olhar se faz necessário, um olhar que busque captar as potências das redes cotidianas (FERRAÇO, 2007), daquilo que acontece em suas zonas impensadas, e potencialize cada pequeno modo de crer no mundo. Cada mínimo gesto serviria como uma ocasião, guardaria uma potência capaz de nos violentar e de nos levar a pensar. Gestos que só podem surgir quando de uma pesquisa, uma experimentação tateante, capaz de nos surpreender, pois, como argumentam alguns autores: "a vida de uma pesquisa é algo intrigante. Sujeita à sorte, ao tempo, aos lugares, à hora, ao perigo" (OLIVEIRA; PARAíSO, 2012, p. 161).

\section{Considerações finais}

A arte do retrato elaborada por Montaigne na aurora da modernidade implica a construção de um espaço de pensamento singular no qual é possível experimentar ensaiar o impensável. Esse espaço, construído tanto a partir de uma imersão na mundanidade quanto no embate com os valores transcendentais vigentes, implica riscos, os quais passam a ser tomados como elementos constitutivos dessa nova geografia de pensamento.

A partir da triangulação de forças entre Montaigne, Vila Matas e DeleuzeGuattari, poderíamos afirmar que um dos riscos mais potentes nessa arte do retrato em pesquisa educacional encontra-se na força de desaparição. Ensaiar uma tal pintura, interessada em apreender a passagem e o devir, implica uma entrega aos loucos fluxos do pensamento e, como paga, a perda de qualquer porto seguro - 0 cogito, por exemplo. Seguimos de ideia em ideia, procurando saturá-las e levá-las aos seus limites, até aquele ponto no qual uma ideia se encontra com outra e, 


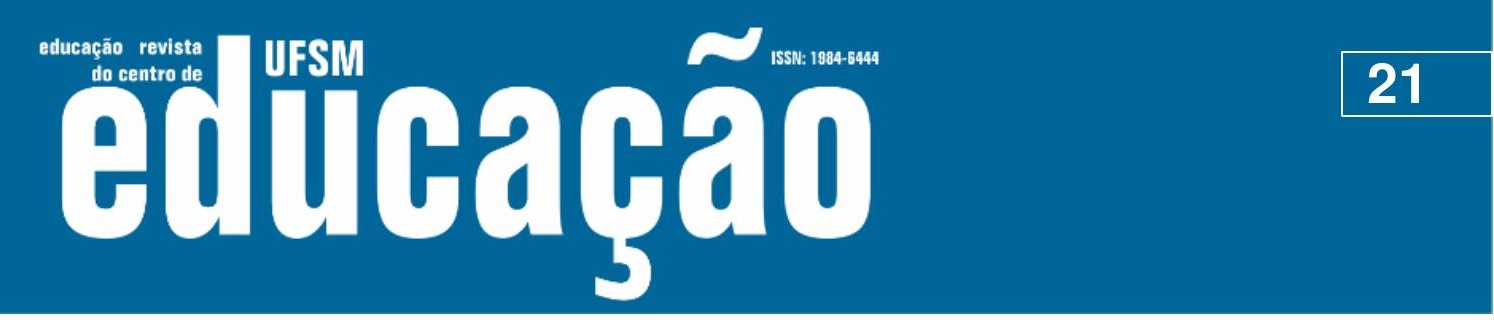

ISSN: 1984-6444 | http://dx.doi.org/10.5902/1984644444292

dessas núpcias, alguma outra coisa possa emergir, algo sem nome, um retrato da ordem do impensável. Esse movimento, ensaístico por excelência, seria a expressão máxima da desaparição.

Desparecer, seguindo Enrique Vila-Matas (2005), não implicaria um movimento de retração ou apagamento, mas o contrário. Desaparecer seria a expressão da mais voraz e absoluta entrega ao mundo, desfrutando de suas potências criativas, de modo que possamos ensaiá-lo lentamente e nos deleitarmos com as experimentações por ele propiciadas. Desaparecer, por conseguinte, não significaria se evadir ou declinar das coisas da vida, mas se empanturrar e se impregnar delas, ainda que das mais triviais. Uma tal força, vislumbrada pelo pensador catalão no pensamento de Montaigne, exige 0 apagamento das individualidades, o borrar da fronteira entre subjetividade e objetividade, e o abandono de toda e qualquer teoria. Nesse espaço, nada resta senão o ensaiar, senão viver o ensaio como gesto capaz de permitir a experimentação de mundos outros.

\section{Referências}

BARROS, Laura Pozzana de; KASTRUP, Virgínia. "Cartografar é acompanhar processos". In: PASSOS, Eduardo; KASTRUP, Virgínia; ESCÓSSIA, Lilliana (orgs.). Pistas do Método da Cartografia: pesquisa-intervenção e produção de subjetividade. Porto Alegre: Sulina, 2012. p. 52-75.

BARROS, Laura Pozzana; PASSOS, Eduardo. "Por uma política da narratividade". In: PASSOS, Eduardo; KASTRUP, Virgínia; ESCÓSSIA, Lilliana (orgs.). Pistas do Método da Cartografia: pesquisa-intervenção e produção de subjetividade. Porto Alegre: Sulina, 2012. p. 172-205.

COSTA, Gilcilene Dias da. "Curricularte: experimentações pós-críticas em educação". Educação \& Realidade, Porto Alegre, v. 36, n. 1, jan-abr. 2011, p. 279293. https://seer.ufrgs.br/educacaoerealidade/article/view/11554/11577. Último acesso em: 02 de janeiro de 2019.

DELEUZE, Gilles. Cinema 2: a imagem-tempo. Tradução de Eloisa de Araújo Ribeiro. São Paulo: Brasiliense, 2007b. 


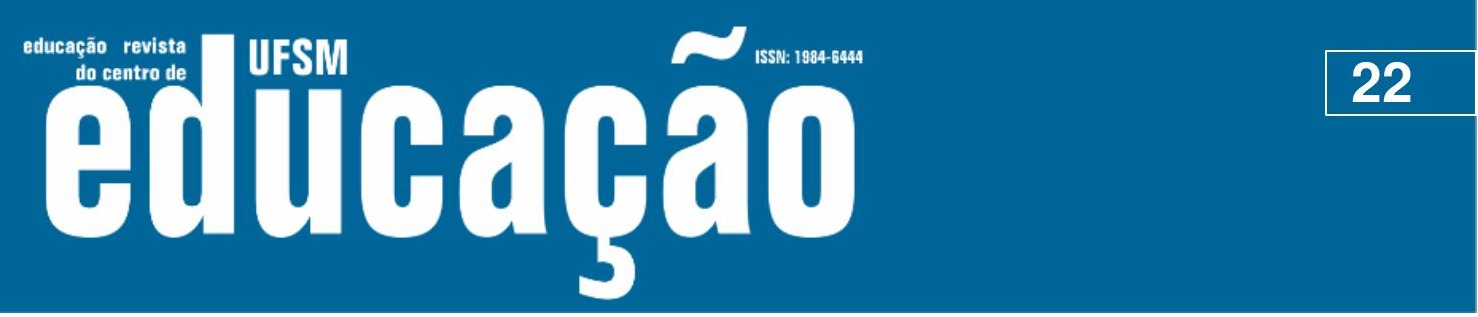

ISSN: 1984-6444 | http://dx.doi.org/10.5902/1984644444292

DELEUZE, Gilles. Crítica e Clínica. Tradução Peter Pál Pelbart. São Paulo: Editora 34, 1997.

DELEUZE, Gilles. Diferença e Repetição. Trad. Luiz B. Orlandi e Roberto Machado. São Paulo: Graal, 1988.

DELEUZE, Gilles. Francis Bacon: lógica da sensação. Tradução de Roberto Machado (coord.). Rio de Janeiro: Jorge Zahar Editores, 2007a.

DELEUZE, Gilles. Nietzsche e a filosofia. Tradução: Edmundo Fernandes Dias e Ruth Jofflily Dias. Rio de Janeiro: Editora Rio, 1976.

DELEUZE, Gilles. Proust e os signos. Tradução de Antônio Carlos Piquet e Roberto Machado. Rio de Janeiro: Forense Universitária, 2010.

DELEUZE, Gilles; GUATTARI, Félix. Mil Platôs: capitalismo \& esquizofrenia, vol. 1. Trad. Aurélio Guerra Neto e Célia Pinto Costa. São Paulo: Editora 34, 1995.

DELEUZE, Gilles; GUATTARI, Félix. O que é a Filosofia? Trad. Bento Prado Jr. e Alberto Alonso Muñoz. São Paulo: Editora 34, 1992.

DESCARTES, René. Discurso do Método. Trad. Maria Ermantina de Almeida Prado Galvão. São Paulo: Martins Fontes, 2009.

DESCARTES, René. Meditações Metafísicas. Trad. Maria Ermantina de Almeida Prado Galvão. São Paulo: Martins Fontes, 2011.

ESCÓSSIA, Liliana de; TEDESCO, Silvia. "O coletivo de forças como plano de experiência cartográfica”. In: PASSOS, Eduardo; KASTRUP, Virgínia; ESCÓSSIA, Lilliana (orgs.). Pistas do Método da Cartografia: pesquisa-intervenção e produção de subjetividade. Porto Alegre: Sulina, 2012. p. 92-108.

FERRAÇO, Carlos Eduardo. "Pesquisa com o cotidiano”. Educação \& Sociedade, Campinas, vol. 28, n. 98, jan-abr. 2007, p. 73-95. Disponível em: http://www.scielo.br/pdf/es/v28n98/a05v2898.pdf. Último acesso em: 02 de janeiro de 2019.

FOUCAULT, Michel. As Palavras e as Coisas. Trad. Salma Tannus Muchail. São Paulo: Martins Fontes, 2009.

FOUCAULT, Michel. História da Loucura na idade clássica. Trad. José Teixeira Coelho Netto. São Paulo: Perspectiva, 1978.

MONTAIGNE, Michel de. Os Ensaios: livro I. Trad. Rosemary Costhek Abílio. São Paulo: Martins Fontes, 2002. 


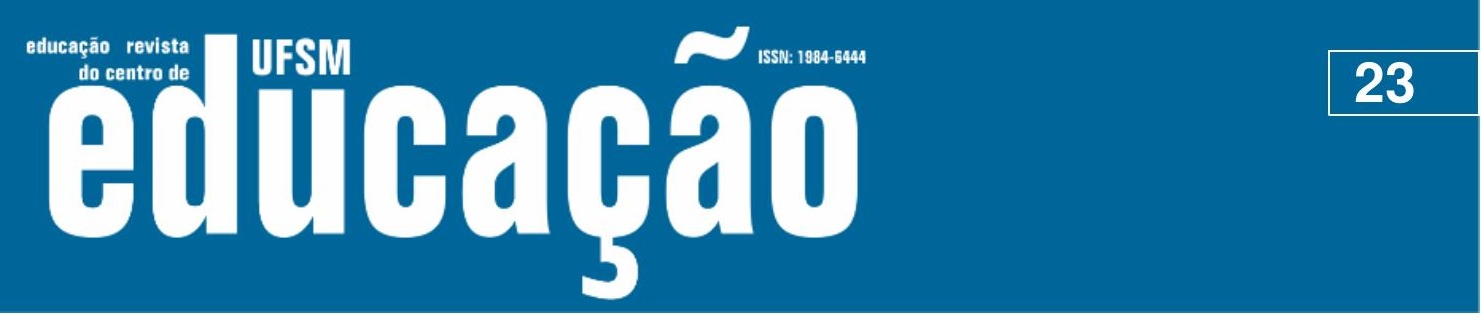

ISSN: 1984-6444 | http://dx.doi.org/10.5902/1984644444292

OLIVEIRA, Ranniery Moreira de; PARAísO, Marlucy Alves. "Mapas, dança, desenhos: a cartografia como método de pesquisa em educação". Pro-Posições, Campinas, v. 23, n.3, set-dez. 2012, p. 159-178. Disponível em: http://www.scielo.br/pdf/pp/v23n3/10.pdf. Último acesso em: 02 de janeiro de 2019.

PRESTES, Nadja Hermann. "Metafísica da subjetividade na educação: as dificuldades do desvencilhamento". Educação \& Realidade, Porto Alegre, v. 22, n. 1, jan-jun. 1997, p. 81-94. Disponível em: https://seer.ufrgs.br/educacaoerealidade/article/view/71465/40541. Último acesso em: 02 de janeiro de 2019.

RIBEIRO, Cintya Regina. “'Pensamento do fora', conhecimento e pensamento em educação: conversações com Michel Foucault". Educação \& Pesquisa, São Paulo, v. 37, n. 3, jul-set. 2011, p. 613-628.

ROUSSEL, Raymond. Como Escrevi Alguns dos meus Livros. Trad. Fabiano Viana. Florianópolis: Cultura e Barbárie, 2015.

VILA-MATAS, Enrique. Doutor Pasavento. Trad. José Geraldo Couto. São Paulo: Cosac Naify, 2009.

VILA-MATAS, Enrique. O Mal de Montano. Trad. Celso Mauro Paciornik. São Paulo: Cosac Naify, 2005.

VILA-MATAS, Enrique. Perder Teorías. Madrid: Seix Barral, 2010.

VINCI, Christian F. R. G. Lenta Voragem: experimentação e prudência na pesquisa educacional deleuzo-guattariana. Tese de Doutorado. São Paulo: Universidade de São Paulo, 2019.

VINCI, Christian F.R.G.; RIBEIRO, Cintya R. Experimentações com a Pesquisa Educacional Deleuze-Guattariana no Brasil. Educação \& Realidade, Porto Alegre, v. 43, n. 1, p. 23-44, mar. 2018. Disponível em http://www.scielo.br/scielo.php?script=sci_arttext\&pid=S2175-

62362018000100023\&lng=pt\&nrm=iso. Último acesso em: 14 de dezembro de 2019.

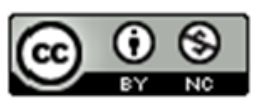

This work is licensed under a Creative Commons Attribution-NonCommercial 4.0 International (CC BY-NC 4.0) 